\title{
Perbandingan Metode Double Exponential Smoothing dan Least Square untuk Sistem Prediksi Hasil Produksi Teh
}

\author{
Muhammad Bagus Nurkahfi', Victor Wahanggara ${ }^{2}$, Bakhtiyar Hadi Prakoso ${ }^{3}$ \\ 1,2Jurusan Teknik Informatika, Universitas Muhammadiyah Jember \\ ${ }^{3}$ Jurusan Kesehatan, Politeknik Negeri Jember \\ Inurkahfi.bagus@gmail.com, ${ }^{2}$ victorwahanggara@unmuhjember.ac.id, ${ }^{3}$ bakhtiyar.hp@polije.ac.id
}

\begin{tabular}{|c|c|}
\hline Keywords: & ABSTRACT \\
\hline $\begin{array}{l}\text { Tea, } \\
\text { Double Exponential Smoohting, } \\
\text { Least Square, } \\
\text { Prediction, }\end{array}$ & $\begin{array}{l}\text { Tea is one of the mainstay commodities of Indonesian plantation. In order to meet } \\
\text { market demand, it is necessary to plan the right production needs, so that the amount } \\
\text { of production capacity and market demand is balanced. To meet the needs of the } \\
\text { right production requires good planning. The way that can be done is by making } \\
\text { predictions. In this study, the prediction of tea production was carried out using the } \\
\text { Double Exponential Smothing and Least Square methods. From the test results, it } \\
\text { was found that the MAPE value of the Double Exponential Smoothing method, the } \\
\text { most optimal } \alpha \text { value is } \alpha 0.1 \text { with a MAPE value of } 18.084 \% \text { and for the Least } \\
\text { Square method the MAPE value is } 17.008 \% \text {. }\end{array}$ \\
\hline
\end{tabular}

\section{Kata Kunci}

Teh,

Double Exponential Smoothing,

Least Square,

Prediksi,

\begin{abstract}
ABSTRAK
Teh meruapakan salah satu komoditas andalan perkebuanan nusantara. Dalam rangka memenuhi kebutuhan pasar perlu direncananakan kebutuhan produksi yang tepat, sehingga antara jumlah kapasitas produksi dengan permintaan pasar seimbang. Untuk memenuhi kebutuhan produksi yang tepat perlu perencanaan yang baik. Cara yang dapat dilakukan adalah dengan melakukan prediksi. Didalam penelitian ini dilakukan prediksi produksi teh dengan menggunakan metode Double Exponential Smothing dan Least Square. Dari hasil uji didapatkan nilai MAPE metode Double Exponential Smoothing nilai $\alpha$ yang paling optimal adalah $\alpha 0,1$ dengan nilai MAPE $18,084 \%$ dan untuk metode Least Square nilai MAPE-nya adalah 17,008 \%.
\end{abstract}

\section{Korespondensi Penulis:}

Bakhtiyar Hadi Prakoso,

Politeknik Negeri Jember,

Jl. Mastrip 164 Jember,

Email: bakhtiyar.hp@polije.ac.id

\section{PENDAHULUAN}

Hampir semua perusahaan yang bergerak di bidang industri saat ini menghadapi tingkat persaingan yang semakin ketat. Hal tersebut mengharuskan perusahaan untuk dapat merencanakan kegiatan produksi dengan baik, sehingga diharapkan keuntungan perusahaan akan meningkat. Terkait hal tersebut suatu sistem yang dapat membantu mengatasi masalah produksi yang ada pada setiap perusahaan. Proses perencaan produksi harus didukung keputsan yang tepat, agar perencanaan bisa optimal. Proses pendukung keputusan yang baik akan menghasilkan keputusan yang tepat jika data-data yang dipergunakan untuk mengambil keputusan tepat dan akurat. Salah satu data dukungnya adalah data prediksi. Sistem prediksi dapat digunakan untuk memprediksi jumlah produksi pada perieode sebelumnya.

Salah satu metode yang dipakai dalam prediksi adalah metode Double Exponential Smothing. Banyak penilitan-penelitian terkait dengan prediksi yang menggunakan Doubel exponential Smoothing diantaranya penelitian yang dilakukan oleh, Rosyid dimana didalam penelitiannya memakai metode double exponttial smoothing dalam menyelesaikan prediksi harga bahan-bahan pangan di pulau Jawa. Hasil prediksi menunjukkan nilai MAPE rata-rata dibawah $10 \%$ [1]. Chusyairi dkk, menggunakan metode double exponential smoothing untuk memprediksi laporan kepolisian yang hilang, dimana data yang digukan merupakan data-data terkait dengan laporan-laporan 
kepolisian [2], Metode double exponential smothing juga dipergunakan untuk memprediksi tingkat reservasi kamar hotel di Pulau Kalimantan. Ramadia dkk mengambil data tahun 2014 sampai dengan 2018 untuk memprediksi hotel. Hasil peramalan menunjukkan nilai MSE terbail sebesar 19,27 dengan nilai alpha 0.1[3].

Least square merupakan sebuah metode yang digunakan untuk membantu prediksi. Metode ini merupakan metode yang dibangun berdasarkan konsepe stattistik. Dengen dkk mencoba memprediksi stok obat dengan menggunakan metode Least Square. Data yang dipergunakan merupakan data obat dengan periode bulan Januari sampai dengen Nopember. dari penelitian tersebut didapatkan hasil Mean Absolute Deviation (MAD) sebesar 51.20 \%, Mean Square Error (MSE) sebesar 66.29 \% dan Mean Absolute Percentage Error (MAPE) sebesar 10\% . Hal ini cukup efektif karena tingkat error tidak melebihi 10\%[4].

Teh meruapakan salah satu komoditas andalan perkebuanan nusantara dimana pengelolaannya dilakukan oleh PTP Nusantara. Untuk memenuhi kebutuhan pasar perlu direncananakan kebutuhan produksi yang tepat, sehingga antara kapasitas produksi dengan permintaan pasar terjadi keseimbangan. Salah satu cara yang dapat dilakukan adalah dengan membuat sebuah sistem pendukukung kepusan untuk membantu dalam merencanakan produksi dengan menggunkan metode predikisi. Pada artikel ini akan dibuat aplikasi untuk dibandingkan dua metode prediksi yaitu double exponential smohting dan least squere dengan data produksi the. Data diambil dari salah satu perusahan yang mengelola produduksi teh di Kabupaten Blitar Jawa Timur.

\section{METODE PENELITIAN}

\subsection{Exponential Smoothing}

Smoothing adalah mengambil rata - rata dari nilai pada beberapa periode untuk menaksir nilai pada suatu periode, Exponential Smoothing adalah suatu peramalan rata - rata bergerak yang melakukan pembobotan menurun secara exponential terhadap nilai - nilai observasi yang lebih dulu. Metode Exponential Smoothing merupakan pengembangan dari metode Moving Average. Dalam metode ini peramalan dilakukan dengan mengulang perhitungan secara terus menerus dengan menggunakan data baru. Peramalan Expinential Smoothing merupakan salah satu kategori metode time series yang menggunakan pembobotan data masa lalu secara eksponensial. Dalam kategori ini terdapat beberapa metode yang umum dipakai, antara lain metode Single Exponential Smoothing, Double Exponential Smoothing, dan Triple Exponential Smooting

Metode Double Exponential Smoothing digunakan ketika data menunjukkan adanya trend. Exponential smoothing dengan adanya trend seperti pemulusan sederhana kecuali bahwa dua komponen harus diperbarui setiap periode - level dan trendnya. Level adalah estimasi yang dimuluskan dari nilai data pada akhir masing - masing periode. Trend adalah estimasi yang dihaluskan dari pertumbuhan rata - rata pada akhir masing - masing periode. Rumus untuk Double Exponential Smoothing adalah [5] :

$$
\begin{aligned}
& \mathrm{S}_{\mathrm{t}}=\alpha \mathrm{X}_{\mathrm{t}}+(1-\alpha) \mathrm{S}_{\mathrm{t}-1} \\
& \mathrm{~S}^{\prime}{ }_{\mathrm{t}}=\alpha \mathrm{S}_{\mathrm{t}}+(1-\alpha) \mathrm{S}_{\mathrm{t}-1} \\
& \alpha_{\mathrm{t}}=\mathrm{S}_{\mathrm{t}}+\left(\mathrm{S}^{\prime} \mathrm{t}-\mathrm{S}{ }^{\prime} \mathrm{t}\right)=2 \mathrm{~S}_{\mathrm{t}}{ }-\mathrm{S}^{\prime}{ }_{\mathrm{t}-1} \\
& \mathrm{~b}_{\mathrm{t}}=\frac{\alpha}{1-\alpha}\left(\mathrm{S}_{\mathrm{t}}{ }_{\mathrm{t}}-\mathrm{S}^{\prime}{ }_{\mathrm{t}}\right) \\
& \mathrm{F}_{\mathrm{t}+\mathrm{m}}=\alpha_{\mathrm{t}}+\mathrm{b}_{\mathrm{t}} \text {, dimana } \mathrm{m}=1 \\
& \text { Dimana : } \\
& \mathrm{X}_{\mathrm{t}}=\text { Data pada periode } \mathrm{t} \\
& \mathrm{S}_{\mathrm{t}}{ }_{\mathrm{t}}=\text { Nilai pemulusan } 1 \text { periode } \mathrm{t} \\
& \mathrm{S}^{\prime}{ }_{\mathrm{t}}=\text { Nilai pemulusan } 2 \text { periode } \mathrm{t} \\
& \mathrm{S}_{\mathrm{t}-1}=\text { Nilai pemulusan pertama sebelumnya }(\mathrm{t}-1) \\
& \mathrm{S}{ }{ }_{\mathrm{t}-1}=\text { Nilai pemulusan kedua sebelumnya }(\mathrm{t}-2) \\
& \text { A }=\text { Konstanta pemulusan } \\
& \alpha_{\mathrm{t}} \quad=\text { Intersepsi pada periode } \mathrm{t} \\
& \mathrm{b}_{\mathrm{t}}=\text { Nilai trend pada periode } \mathrm{t} \\
& \mathrm{F}_{\mathrm{t}+\mathrm{m}}=\text { Hasil peramalan untuk periode } \mathrm{t}+1 \\
& \mathrm{~m}=\text { Jumlah periode waktu kedepan }
\end{aligned}
$$

Agar dapat menggunakan persamaan diatas, nilai $\mathrm{S}_{\mathrm{t}-1}$ dan $\mathrm{S}_{\mathrm{t}-1}$ harus tersedia. Tetapi pada saat $\mathrm{T}=1$, nilai tersebut tidak tersedia, jadi nilai - nilai ini harus tersedia di awal.

Disini metode pemulusan eksponensial tunggal tidak cukup baik diterapkan jika datanya bersifat tidak stasioner atau memiliki trend, oleh karena itu penulis menggunakan metode double exponential smoothing karena data yang di teliti memiliki trend yang ditandai dengan adanya kecenderungan arah data bergerak naik dan turun pada jangka panjang.

\subsection{Metode Kuadrat Terkecil (Least quare)}

Metode Least Square adalah metode peramalan yang digunakan untuk melihat trend dari data deret waktu (Sofyan Assauri, 1991). Metode Least Square adalah salah satu metode pendekatan yang digunakan untuk regresi 
ataupun pembentukan persamaan dari titik - titik data diskretnya (dalam permodelan), dan analisis sesatan pengukuran (dalam validasi model). Dengan rumus sebagai berikut [6]:

$$
\mathrm{Y}=\mathrm{a}+\mathrm{bx}
$$

Keterangan :

Y : Jumlah penjualan

$\mathrm{a} \& \mathrm{~b} \quad$ : Koefisien

$\mathrm{x} / \mathrm{t} \quad$ : Waktu tertentu dalam bentuk kode

Dalam menentukan nilai $\mathrm{x} / \mathrm{t}$ seringkali digunakan teknik alternatif dengan memberikan skor atau kode.

Dalam hal ini dilakukan pembagian data menjadi dua kelompok, yaitu :

1. Data genap, maka skor nilai t nya : ..., -5, $-3,-1,1,3,5, \ldots$

2. Data ganjil, maka skor nilai t nya : ..., -3, -2, $-1,0,1,2,3, \ldots$

Selanjutnya, untuk mengetahui koefisien a dan $\mathrm{b}$ di cari dengan menggunakan rumus :

$$
\mathrm{A}=\frac{\Sigma Y}{n} \quad \mathrm{~B}=\frac{\Sigma X Y}{X^{\prime}}
$$

\subsection{MAPE (Mean Absolute Precentage Error)}

MAPE merupakan perhitungan perbedaan antara data asli dan data hasil peramalan. Perbedaan dari perhitungan tersebut diabsolutkan sehingga bernilai positif, dan kemudian dihitung ke dalam bentuk presentase terhadap data asli. Hasil presentase tersebut kemudian didapatkan nilai meannya.). MAPE lebih banyak digunakan untuk mengukur akurasi time series, khususnya untuk mengukur trend. Rumus $M A P E$ adalah sebagai berikut [7] :

$$
\begin{aligned}
& \text { MAPE }=\frac{1}{n} \sum_{t=1}^{n} \frac{|X t-F t|}{X t} 100 \\
& \text { Keterangan : } \\
& \mathrm{X}_{\mathrm{t}}=\text { Data aktual pada periode ke } \mathrm{t} \\
& \mathrm{F}_{\mathrm{t}}=\text { Nilai ramalan pada periode ke } \mathrm{t} \\
& \mathrm{n} \quad=\text { Banyaknya periode waktu }
\end{aligned}
$$

\section{HASIL DAN ANALISIS}

Analisis dilakukan dengan mengambil data produksi teh periode tahun 2012 sampai dengan tahun 2016. Data masukan berupa data per bulan. Analisis dihitung dengan membuat sebuah program di Java. Berikut adalah form input data yang digunakan untuk menginputkan data hasil produksi. Pada form ini pengguna bisa memasukan datadata produksi teh

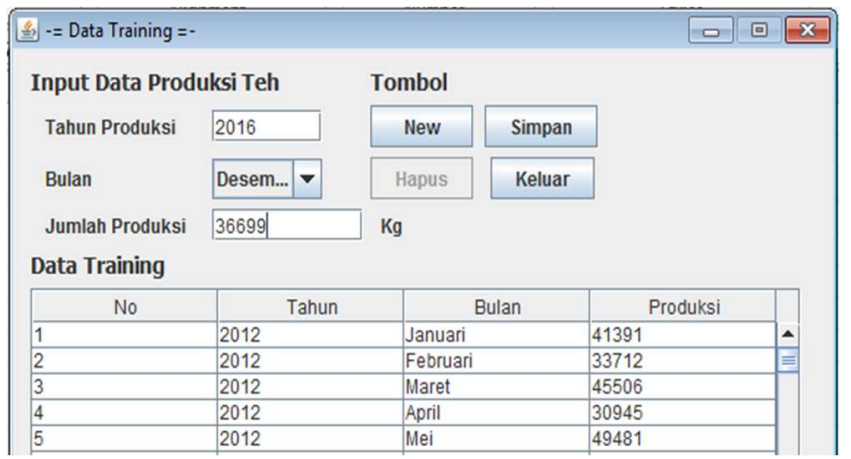

Gambar 1. Form masukan data

Dalam penelitia ini penulis memasukkan 60 data produksi dari tahun 2012 sampai dengan 2016 yang dijadikan sebagai data training untuk memprediksikan hasil produksi teh pada bulan berikutnya menggunakan metode Least Square dan Double Exponential smoothing.

Analisa pertama dilakukan dengan menghitung produksi the dengan menggunakan metode Double Exponential Smoothing. Gambar dibawah ini adalah merupakan hasil perhitungan yang telah dilakukan 


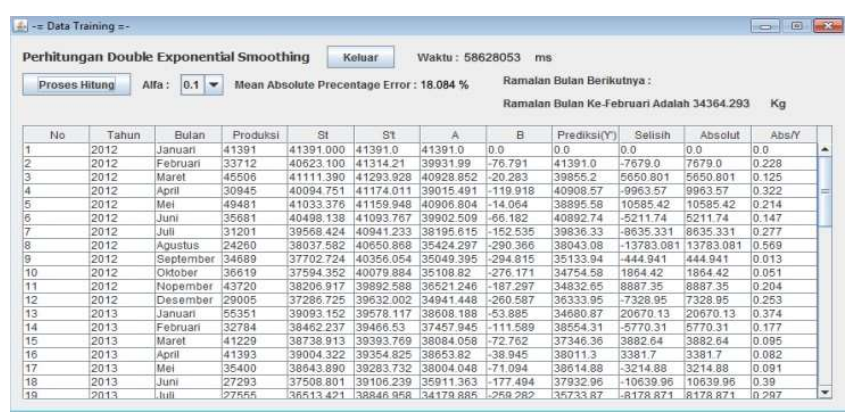

Gambar 2. Form Perhitungan Double Exponential Smoothing

Uji dilakukan dengan menghitung MAPE untuk masing-masing nilai alpha antara 0.1 sampai dengan 0.9. Dari perhitungan menggunakan aplikasi didapatkan nilai MAPE sebagai berikut.

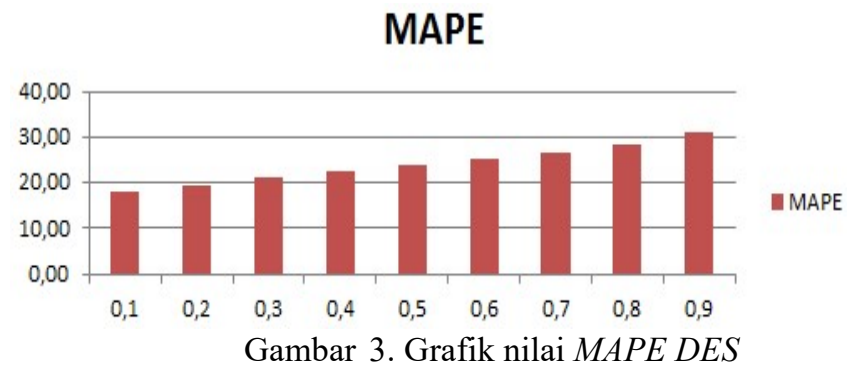

Berdasarkan data pada gambar diatas nilai $M A P E$ mulai dari alpha $=0,1$ sampai dengan 0,9 cenderung meninggkat nilai $M A P E$ terkecil didapatkan dari nilai alpha 0,1 . Oleh karena itu nilai alpha yang digunakan adalah dengan menggunakan nilai $\alpha=0,1$. Selanjutkan akan dilakuakan perhitungan nilai prediksi untuk masing-masing periode dengan menggunakan metode Double Expoential Smoothing dengan nilai alpha =0,1. Gambar dibawah ini merupakan hasil perhitungan prediksinya.

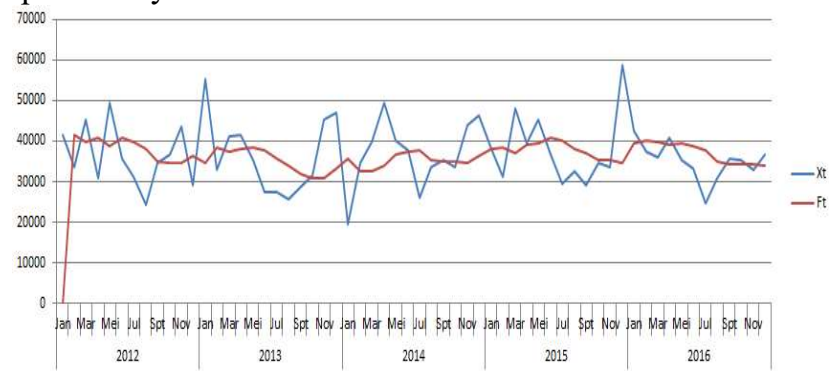

Gambar 4 Grafik Perbandingan Nilai Aktual dan Prediksi DES

Grafik biru menunjukkan nilai actual sedangakan grafik merah menunjukkan nilai prediksi. Dari perhitungan aplikasi didapatkan hasil prediksi sebesar $36204,793 \mathrm{Kg}$ untuk periode berikutnya.

Analisa berikutnya dilakukan dengan menghitung produksi teth dengan menggunakan metode Least Square. Gambar dibawah ini adalah merupakan hasil perhitungan yang telah dilakukan

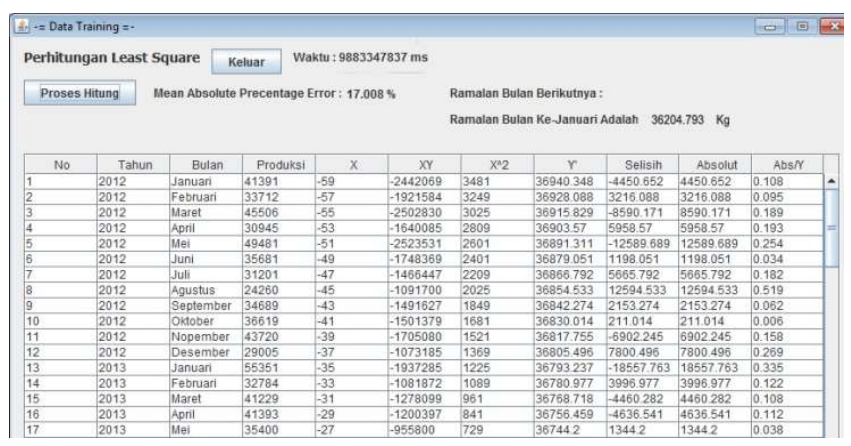

Gambar 5. Form Perhitungan Least Square

Dari perhitungan metode least sqare pada aplikasi, didalapatkan perbandingan nilai prediksi dan nilai actual yang selanjutnya dapat dilihat pada gambar berikut ini. 


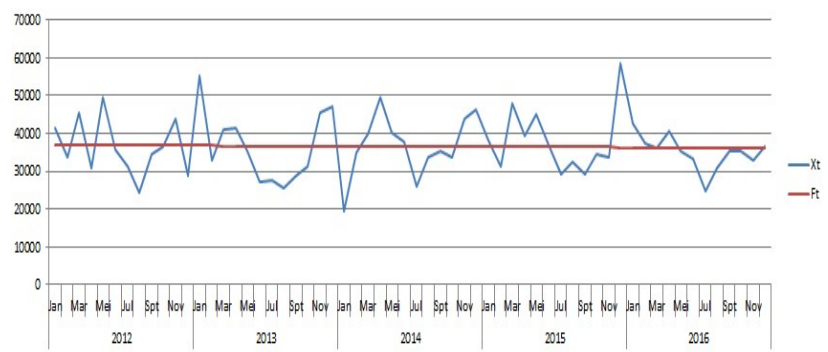

Gambar 6 Grafik Perbandingan data Training dan Prediksi LS

Berdasarkan gambar dapat dilihat grafik perbandingan hasil prediksi metode Least Square. Grafik biru menunjukkan nilai actual sedangakan grafik merah menunjukkan nilai prediksi Terlihat bahwa hasil prediksi dan data training perbedaannya cukup jauh pada setiap periode, hasil prediksi dari metode Least Square cenderung berada di tengah atau rata - rata dari keseluruhan data training. From berikut merupakan perbandingan $M A P E$ serta kecepatan dari setiap proses prediksi. Serta akan ditampilkan kesimpulan metode mana yang nantinya akan menghasilkan nilai prediksi yang paling optimal.

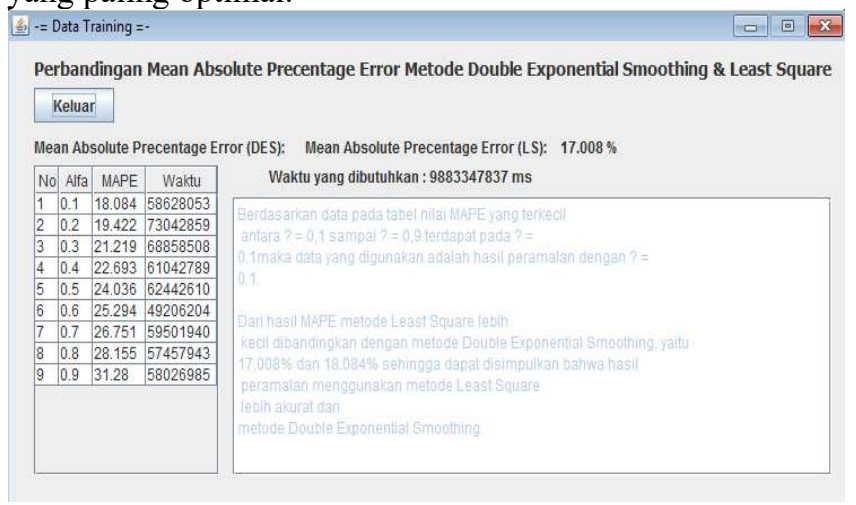

Gambar 7 Hasil MAPE dan Kecepatan Proses

Berdasarkan uji coba pada gambar 7 didapat perbandingan antara metode Double Exponential Smoothing dan Least Square. Pada metode Double Exponential Smoothing nilai alfa antara 0,1 sampai dengan 0,9 yang memiliki tingkat eror terkecil adalah alfa 0,1 dengan nilai MAPE = 18,084 \% dengan Kecepatan 58628053 ms. Sedangkan pada metode Least Square nilai MAPE $=17,008 \%$ dengan kecepatan $=9883347837 \mathrm{~ms}$

\section{KESIMPULAN}

Dari hasil Dari hasil nilai MAPE metode Double Exponential Smoothing nilai $\alpha$ yang paling optimal adalah $\alpha$ 0,1 dengan nilai $M A P E 18,084 \%$ dan nilai $\alpha$ terbesar adalah $\alpha$ 0,9 dengan nilai MAPE 31,280 dan untuk metode Least Square nilai MAPE-nya adalah 17,008 \%. sehingga dapat disimpulkan bahwa metode Least Square lebih akurat dibandingkan metode Double Exponential Smoothing karena nilai MAPE dari metode Least Square lebih mendekati dibandingkan dengan metode Double Exponential Smoothing. Proses prediksi pada sistem antara perhitungan metode Least Square dan Double Exponential Smoothing pada setiap alfanya lebih cepat metode Double Exponential Smoothing dengan kecepatan proses pada $\alpha=0,1$ yaitu $58628053 \mathrm{~ms}$. Sedangkan pada metode Least Square proses prediksinya adalah $9883347837 \mathrm{~ms}$. Untuk penelitian selanjutnya dapat dilakukan dengan mencoba metode-metode prediksi yang lainnya. Sehingga akan diperoleh metode paling efektif digunakan untuk melakukan prediksi teh

\section{UCAPAN TERIMA KASIH}

Ucapan terima kasih dapat diperuntukkan kepada pihak-pihak yang telah membantu dalam penelitian ini yaitu Universitas Muhammadiyah Jember dimana tempat penulis menyelesaikan studi

\section{REFERENSI}

[1] H. A. Rosyid, T. Widiyaningtyas, and N. F. Hadinata, "Implementation of the Exponential Smoothing Method for Forecasting Food Prices at Provincial Levels on Java Island," Proc. 2019 4th Int. Conf. Informatics Comput. ICIC 2019, 2019, doi: 10.1109/ICIC47613.2019.8985872. 
[2] A. Chusyairi, N. S. P. Ramadar, and Bagio, "The use of exponential smoothing method to predict missing service e-report," Proc. - 2017 2nd Int. Conf. Inf. Technol. Inf. Syst. Electr. Eng. ICITISEE 2017, vol. 2018Janua, pp. 39-44, 2018, doi: 10.1109/ICITISEE.2017.8285535.

[3] Ramadiani, N. Wardani, A. Harsa Kridalaksana, M. Labib Jundillah, and Azainil, "Forecasting the Hotel Room Reservation Rate in East Kalimantan Using Double Exponential Smoothing," Proc. 2019 4th Int. Conf. Informatics Comput. ICIC 2019, 2019, doi: 10.1109/ICIC47613.2019.8985916.

[4] N. Dengen, Haviluddin, L. Andriyani, M. Wati, E. Budiman, and F. Alameka, "Medicine Stock Forecasting Using Least Square Method," Proc. - 2nd East Indones. Conf. Comput. Inf. Technol. Internet Things Ind. EIConCIT 2018, no. Ci, pp. 100-103, 2018, doi: 10.1109/EIConCIT.2018.8878563.

[5] S. G. Makridakis, S. C. Wheelwright, and R. J. Hyndman, Forecasting: Methods and Applications, Third Edit. Willey, 2008.

[6] P. K. Dunn and G. K. Smyth, Generalized Linear Models With Examples in R. New York, NY: Springer New York, 2018.

[7] J. H. Rob and A. George, Forecasting: Principles and Practice, First Edit. Monash: Otext, 2013. 